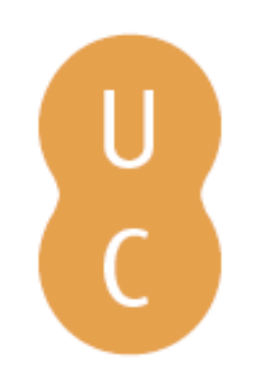

\title{
pompalina
}

\section{Diagnóstico de risco dos imóveis tombados em Bauru/ SP/ Brasil}

Autor(es): $\quad$ Losnak, Sérgio Ricardo; Lopes, Camila Santos Doubek

Publicado por: Imprensa da Universidade de Coimbra; RISCOS - Associação

Portuguesa de Riscos, Prevenção e Segurança

URL

persistente: URI:http://hdl.handle.net/10316.2/34912

DOI: $\quad$ DOI:http://dx.doi.org/10.14195/978-989-96253-3-4_112

Accessed : $\quad$ 26-Apr-2023 16:30:44

A navegação consulta e descarregamento dos títulos inseridos nas Bibliotecas Digitais UC Digitalis, UC Pombalina e UC Impactum, pressupõem a aceitação plena e sem reservas dos Termos e Condições de Uso destas Bibliotecas Digitais, disponíveis em https://digitalis.uc.pt/pt-pt/termos.

Conforme exposto nos referidos Termos e Condições de Uso, o descarregamento de títulos de acesso restrito requer uma licença válida de autorização devendo o utilizador aceder ao(s) documento(s) a partir de um endereço de IP da instituição detentora da supramencionada licença.

Ao utilizador é apenas permitido o descarregamento para uso pessoal, pelo que o emprego do(s) título(s) descarregado(s) para outro fim, designadamente comercial, carece de autorização do respetivo autor ou editor da obra.

Na medida em que todas as obras da UC Digitalis se encontram protegidas pelo Código do Direito de Autor e Direitos Conexos e demais legislação aplicável, toda a cópia, parcial ou total, deste documento, nos casos em que é legalmente admitida, deverá conter ou fazer-se acompanhar por este aviso.

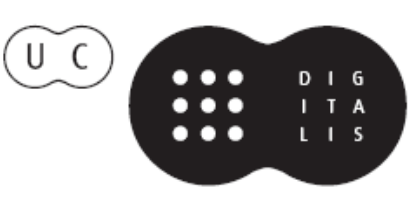



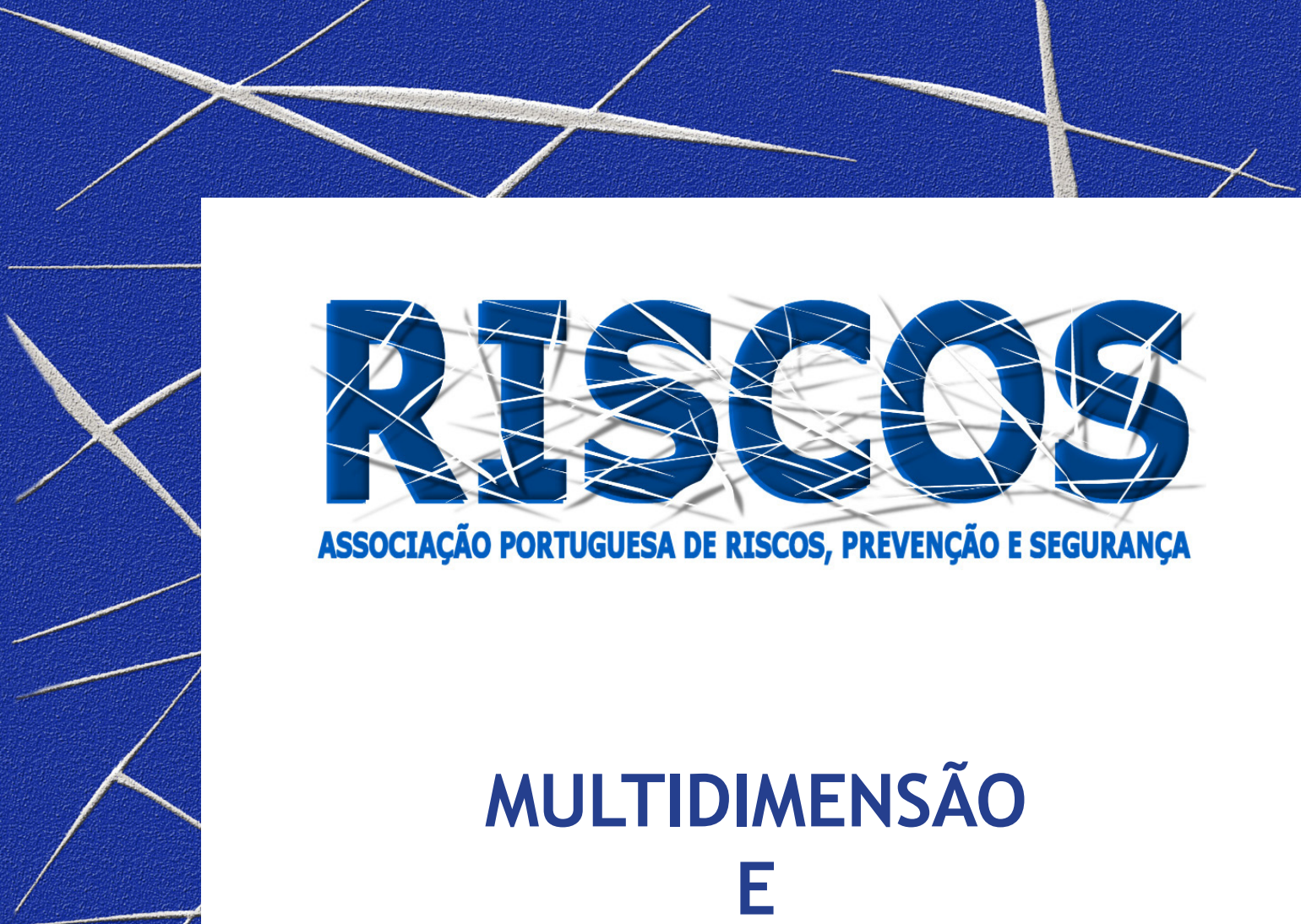

ASSOCIAÇÃO PORTUGUESA DE RISCOS, PREVENCCÃO E SEGURANÇA

MULTIDIMENSÃO

E
TERRITÓRIOS DE RISCO

III Congresso Internacional

I Simpósio Ibero-Americano

VIII Encontro Nacional de Riscos

Guimarães

2014 


\title{
DIAGNÓSTICO DE RISCO DOS IMÓVEIS TOMBADOS EM BAURU/ SP/ BRASIL
}

\author{
Sérgio Ricardo Losnak \\ Departamento de Arquitetura, FAAC da Universidade Estatual Paulista de Bauru \\ sergiolosnak@gmail.com \\ Camila Santos Doubek Lopes \\ Departamento de Geociências, CCE da Universidade Estadual de Londrina \\ uel.camila@gmail.com
}

\begin{abstract}
RESUMO
No Brasil, as políticas públicas de proteção ao patrimônio cultural estão relacionadas aos mecanismo de tombamento. No caso da cidade de Bauru/SP, o tombamento está associado a ações do poder executivo e do Conselho de Defesa do Patrimônio Cultural (CODEPAC). Foi observado empiricamente que essas ações não atingem os objetivos de preservação cultural, arquitetônica e histórica. Assim, este estudo diagnosticou a existência de risco da integridade física que venha ocasionar a descaracterização do bem tombado, bem como, os riscos provocados pelas resignificações e usos desassociados daqueles relativos aos da sua origem. Para tanto, foi realizada pesquisa bibliográfica exploratória e documental descritiva, bem como, visita técnica aos bens tombados que evidenciou a ocupação de $74 \%$ dos bens e sua relação com os riscos. Concluiuse que: (i) o tombamento, quando cerceado de outros mecanismos proporciona riscos a integridade fisica do bem e a paisagem urbana; (ii) a ocupação dos imóveis não está associada à sua conservação e a minização dos riscos (iii) novos sentidos simbólicos atribuidos ao patrimônio ameaçam a identidade local.

Palavras-chave: riscos, vulnerabilidade, tombamento, patrimônio cultural, Bauru/SP.
\end{abstract}

\section{Introdução}

No Brasil, a política de preservação do patrimônio cultural é aplicada pelos poderes públicos, união, estados e municípios, que possuem legislações e metodologias específicas e seguem as orientações da Constituição Federal e parcialmente das convenções internacionais, sendo o mecanismo de tombamento o principal recurso utilizado (BRASIL, 2014). No município de Bauru/ $\mathrm{SP}$, o tombamento se dá por ações do poder público municipal em conjunto com a sociedade civil, por meio do Conselho de Defesa do Patrimônio Cultural - CODEPAC.

Em virtude da ausência de um diagnóstico preciso quanto à situação atual dos imóveis tombados, este trabalho propõe discorrer sobre a efetividade da política de preservação do patrimônio cultural do município, por meio da elaboração de um diagnóstico sobre as formas de uso, conservação, preservação e riscos físicos e simbólicos dos bens imóveis tombados.

Quanto à metodologia, foi realizada pesquisa quali-quantitativa, bibliográfica exploratória e documental em Processos de Tombamentos, Atas e legislações pertinentes ao CODEPAC, além de visitas técnicas a cada um dos bens.

Um bem histórico é aquele que recebe uma titulação pública e tem associado a ele reconhecimento de identidade de determinado grupo humano. As mediações no campo simbólico formadas por afetos, lembranças e memórias, quando se efetivam garantem ao bem determinado nível de preservação (CLAVAL, 2007). Quanto à preservação, mais especificamente de bem material, busca-se a manutenção da sua integridade física e de suas características originais, ao mesmo tempo que se procura tornar o bem acessível às pessoas, colocando-o em uma dimensão pública e coletiva para se estabelecer as diferentes mediações inerentes ao sujeito e ao objeto (BRASIL, 2004). 
Como consequência das forças hegemônicas do capital especulativo imobiliário somado à ineficiência do Estado no cumprimento das legislações que disciplinam o crescimento da cidade, têm-se o constante aumento da população nas cidades brasileiras, juntamente com seu crescimento desordenado, gerando ameaças e riscos à integridade do patrimônio cultural.

Os diferentes riscos e ameaças que os bens culturais estão sujeitos não são exclusivamente associado aos fatores físicos da geografia do lugar mas também aos fatores socioculturais e econômicos (BRASIL, 2013). Para tanto a gestão de risco é imprescindível e envolve diferentes áreas do conhecimento e de campo de atuação profissional, a sinaliza como proteger de fato os bens de relevância para a humanidade e manter estes espaços de reafirmação identitária de modo a assegurar o direito à memória cultural (ZANIRATO, 2010).

\section{A cidade de Bauru}

Bauru teve sua formação inicial no período de desbravamento do interior do Estado de São Paulo. Seu embrião urbano nutria e garantia segurança para as ocupações de terras rumo ao oeste do estado por volta da segunda metade do século XIX. Em terras dos índios Kaigangues, o arraial árido, mais tarde conhecido como a Capital da Terra Branca, se transformou em município em 1896 (BAURU, 1997).

Como frente e suporte para ocupação do oeste, Bauru se tornou "chão de passagem" (SANT 'AGOSTINHO, 1995), principalmente pela construção da Estrada de Ferro Noroeste do Brasil - EFNOB (1905), que parte de Bauru e chega até a cidade de Corumbá, Estado do Mato Grosso Sul, divisa territorial com a Bolívia. Como também pela chegada dos trilhos de mais duas ferrovias que ligava a cidade ao Porto de Santos, a Estrada de Ferro Sorocabana (1904) e Estrada de Ferro da Companhia Paulista (1911), (SILVA, 1957). A cidade de Bauru abriga edificações expressivas com estilos variados como eclético art deco, modernas e contemporâneas, tombadas ou em estudo de tombamento pelo CONDEPHAAT - Conselho de Defesa do Patrimônio Histórico, Arqueológico, Artístico e Turístico do Estado de São Paulo - e CODEPAC.

\section{O CODEPAC}

Criado pela Lei Municipal $n^{\circ}$ 3.486, de 24 de agosto de 1992, com característica consultiva o CODEPAC é composto por 7 representantes da sociedade civil e 4 membros do executivo e tem a função de indicar e elaborar argumentação documental para tombamento que é efetivado por Decreto Municipal por parte do líder do executivo, que tem a prerrogativa de incluir e ou suprimir as proposituras (CODEPAC, 2014).

\section{A pesquisa - metodologia e resultados}

A pesquisa se baseou na observação dos 35 imóveis tombados no município, comparando o estado atual com aquele registrado nos relatórios e fotografias presentes nos Processos de Tombamento, que datam de suas aberturas. Foi possível identificar o nível de ocupação, conservação e descaracterização externa de cada um dos bens (Tabela I) e apontar os riscos associados à materialidade e aos sentidos simbólicos relacionados à identidade da cidade (Tabela II).

\section{Uso e abandono}

Dos 35 imóveis estudados, 26 (74\%) apresentam ocupação total de suas dependências, outros 3 (9\%) possuem ocupação parcial e os outros 6 (17\%) estão totalmente desocupados. Considerando o uso dos imóveis ocupados (26), constatou-se que a maioria, 23 (88\%) desempenham a função 
para a qual foram projetados e 3 (12\%) abrigam outras funções de uso. Quanto ao estado de conservação dos imóveis, se apurou que 13 (37\%) se encontram bem conservados, 9 (26\%) em estado regular e 13 (37\%) não apresentam algum tipo de conservação, comprometendo a preservação de suas características originais.

Quanto aos indícios de alterações das características originais dos imóveis, 19 (54\%) não apresentam sinais significativos de descaracterização, porém os outros 16 (46\%) apresentam intensas alterações. Outro resultado relevante aponta que, $66,7 \%$ dos bens parcialmente ou totalmente desocupados se referem às Estações Ferroviárias.

\begin{tabular}{|c|c|c|c|c|}
\hline \multicolumn{5}{|c|}{ TABELA I - SITUAÇÃO DO BEM TOMBADO } \\
\hline \multicolumn{5}{|c|}{ BENS TOMBADOS EM USO } \\
\hline Hotel Cariani & Hotel & Bom & Ausente & $1 ; 2 ; 3 ; 5 ; 6$ \\
\hline Casa Comercial - Sobrado do Calçadão & Comércio & Bom & Ausente & $1 ; 2 ; 3 ; 6$ \\
\hline Antigo Palacete Pagani & Comércio & Bom & Ausente & $1 ; 2 ; 3 ; 6$ \\
\hline Antigo Grupo Escolar Ernesto Monte & Comércio & Ruim & Parcial & $1 ; 2 ; 3 ; 5 ; 6$ \\
\hline Antiga Casa Lusitana & Comércio & Regular & Parcial & $1 ; 2 ; 3 ; 6$ \\
\hline Edifício Brasil-Portugal & Moradia & Regular & Ausente & $1 ; 2 ; 3 ; 5 ; 6$ \\
\hline Edifício Abelha & Moradia & Bom & Ausente & $1 ; 2 ; 3 ; 6$ \\
\hline Sede da Fazenda Divisa & Moradia & Regular & Ausente & $1 ; 2 ; 3 ; 6$ \\
\hline Sede da Fazenda Val de Palmas & Moradia & Regular & Parcial & $1 ; 2 ; 3 ; 6$ \\
\hline Antiga Casa do Superintendente da NOB & Escritório & Bom & Parcial & $1 ; 2 ; 3 ; 5 ; 6$ \\
\hline Antiga PRG-8 (atual TV TEM) & Escritório & Bom & Ausente & $1 ; 2 ; 3 ; 6$ \\
\hline Casa Aliança Francesa & Escritório & Bom & Parcial & $1 ; 2 ; 3 ; 5 ; 6$ \\
\hline Portal de entrada do Cemitério da Saudade & Escritório & Regular & Ausente & $1 ; 3 ; 6$ \\
\hline Aeroclube de Bauru & Escritório e hangares & Ruim & Parcial & $1 ; 2 ; 3 ; 6$ \\
\hline Fachada da Beneficência Portuguesa & Hospital & Bom & Parcial & $1 ; 2 ; 3 ; 6$ \\
\hline Automóvel Clube de Bauru - Público & Sede da Orquestra & Bom & Ausente & $1 ; 2 ; 3 ; 6$ \\
\hline Grupo Escolar Rodrigues de Abreu & Escola particular & Bom & Parcial & $1 ; 2 ; 3 ; 5 ; 6$ \\
\hline Palácio das Cerejeiras - Público & Prefeitura Municipal & Regular & Parcial & $1 ; 2 ; 3 ; 6$ \\
\hline Quartel Militar - Público & Policia Militar & Bom & Ausente & $1 ; 2 ; 3 ; 6$ \\
\hline \multicolumn{5}{|c|}{ BENS TOMBADOS PARCIALMENTE EM USO } \\
\hline Estação Sorocabana & Desocupado & Ruim & Ausente & $1 ; 2 ; 4 ; 6$ \\
\hline Estação Curuçá & Desocupado & Ruim & Parcial/critico & $1 ; 2 ; 4 ; 5 ; 6$ \\
\hline
\end{tabular}

\section{Riscos}

A visita técnica realizada a cada um dos bens proporcionou, por meio da observação, identificar fatores que ofereçam algum tipo de risco à preservação do bem.

A possibilidade de risco de incêndio é comum a todos os imóveis, porém com graus distintos. 0 transporte de combustível por trem que ocorre as margens dos diversos prédios históricos é um dos fatores de maior risco.

0 trafego de veiculo que impacta no bem tombado pode ser divido em 3 niveis. 0 primeiro é aquele em que o bem se localiza em rua simples com pouco fluxo e à predominância de veículos leves, o segundo nível é aquele em ruas e avenidas com rotas de ônibus urbano e o último esta associado a proximidade da linha férrea, que em virtude de suas condições precárias apresenta um alto índice de descarrilamento de composições ferroviárias. 
A contradição existente entre os riscos, do abandono e do uso, se dá a partir da constatação de que simplesmente o uso de um bem tombado não garante sua preservação. As alterações mais comuns encontradas foram relativas às esquadrias, pintura, volumetria e área envoltória. Já o estado de abandono, ou a ausência formal de uso, provoca uma degradação natural intensificada e grande incidência ocupações irregulares permanentes ou temporária que aumentam em alto grau o risco de alterações e depredações do bem.

Os fatores relacionados ao comprometimento estrutural do bem, são todos aqueles que de alguma forma interferem em suas características originais. Os fatores relacionados a força da natureza, tendo em vista a geografia da região estão relacionados as intempéries. Um dos imóveis esta localizado em área de inundação, agravando sua situação de risco estrutural.

A gestão do patrimônio cultural está associado às políticas publicas estabelecidas nas três instancias do Estado, mas é no município que de fato a preservação se efetiva. Assim, cabe a ele a implantação de políticas publicas relacionas à outros dispositivos de planejamento da cidade, com envolvimento da sociedade civil e da pratica sistêmica de educação patrimonial aos diferentes públicos que formam a cidade (CHAUI, 2006).

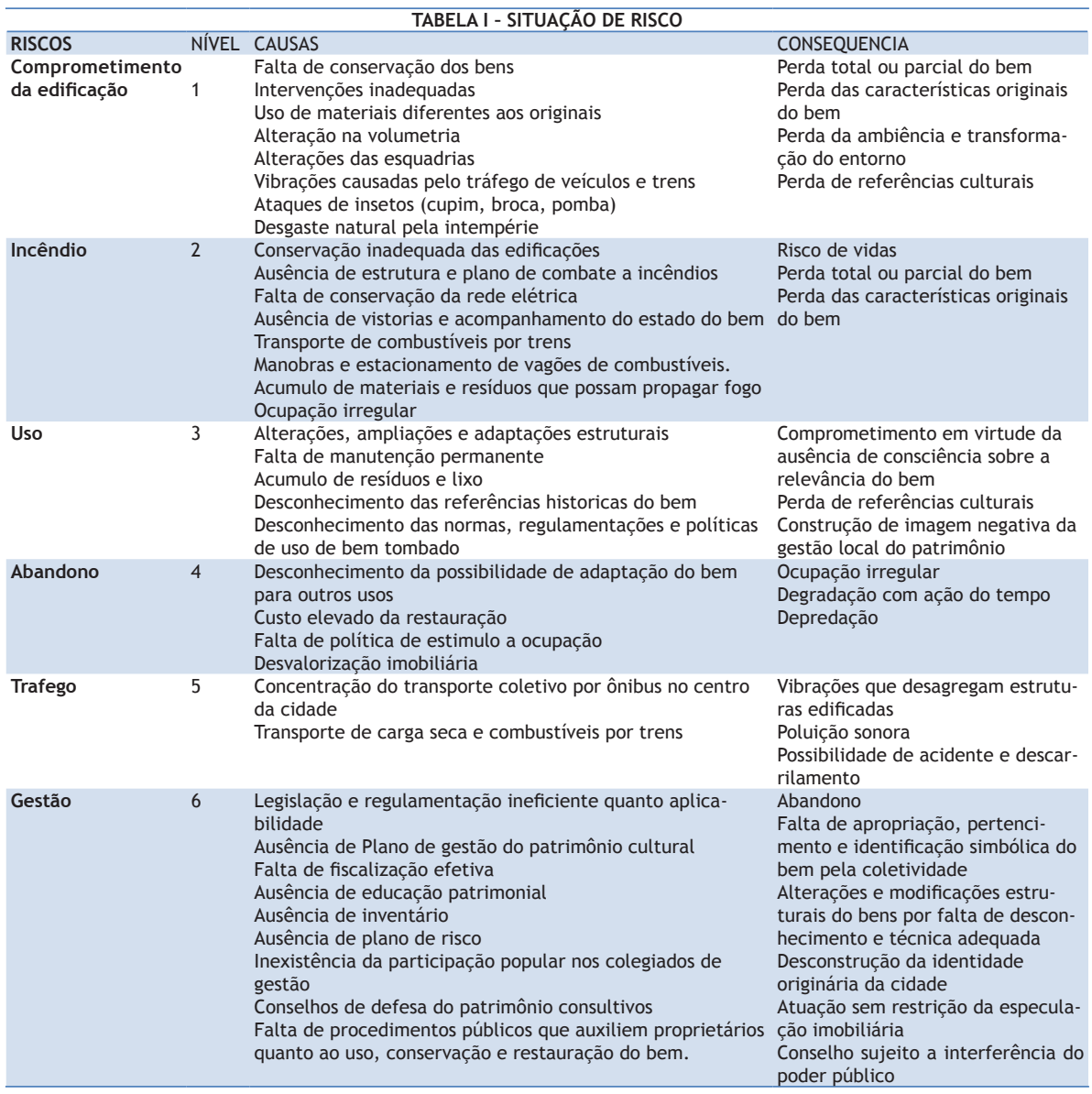




\section{Conclusões}

Com base nos resultados alcançados, pode-se concluir que:

- A gestão do patrimônio tombado se mostra precária por não apresentar planejamento envolvendo ações que acompanhe sistematicamente cada um dos bens. A desocupação, ocupação e os riscos aqui apontados, requerem de início a realização de inventário e um Plano de Gestao de Risco, que possa ser aplicado pelo município de modo a garantir a identidade cultural da cidade.

- Outra situação que causa determinada vulnerabilidade à integridade do bem é a falta de uma estrutura técnica específica que dê sustentação às ações do conselho. Torna-se necessário a formação de uma equipe multidisciplinar que realize sistematicamente estudos pertinentes aos bens e que possa estabelecer uma relação mais próxima com seus proprietários e usuários, oferecendo assessoria e formação no que se diz respeito à política de preservação do Município.

- Apesar da existência de regulamentações que tratam de importantes pontos que possam vir a garantir a salvaguarda do bem, na prática, a legislação não garante sua preservação. 0 método legal acaba provocando uma precarização da posse e do próprio bem. 0 ato de tombar se mostra insuficiente, criando uma dicotomia entre a preservação por ato oficial e a preservação de fato.

\section{Referências Bibliográficas}

BAURU, Prefeitura Municipal de. Edição Histórica 81 anos. Bauru: Focus, 1997.

BRASIL. Ministério da Cultura. Instituto do Patrimônio Histórico e Artístico Nacional - IPHAN. Cartas patrimoniais. Rio de Janeiro: IPHAN, 2004.

BRASIL. Ministério da Cultura. Instituto Brasileiro de Museus. Programa para a gestão de riscos ao patrimônio Musealizado Brasileiro. Rio de Janeiro: IBRAM, 2013.

BRASIL. Ministério da Cultura. Instituto do Patrimônio Histórico e Artístico Nacional - IPHAN. , Tombamento. Disponível em: http://portal.iphan.gov.br/portal/montar PaginaSecao.do?id=17738\&sigla=Institucion altretorno=paginalnstitucional. Acesso em 13 de maio de 2014.

CODEPAC. Disponível em: http://hotsite.bauru.sp.gov.br/codepac/. Acesso em 13 de maio de 2014. CHAUI, Marilena. Cidadania cultural, 0 direito à cultura. São Paulo: Fundação Perceu Abramo, 2006. CLAVAL, Paul. A geografia cultural. 3. ed. Florianópolis: UFSC, 2007.

SANT 'AGOSTINHO, Lúcia Helena F. Bauru, Chão de passagem: entreposto de valores na rota Atlântico Pacífico. São Paulo: Disertação de Mestrado da FAU USP, 1995.

SILVA, Alcides. Roteiro Histórico: uma cidade e uma instituição. Bauru: Tipografia Comercial, 1957. ZANIRATO, Silvia Helena. Experiências de prevenção de riscos ao patrimônio cultural da humanidade. Revista Ambiente \& Sociedade, v. XIII, n. 1, jan-jun. Campinas: UNICAMP, 2010. 